\title{
Smart Logistics using Internet of Things (IoT)- Study
}

\author{
${ }^{1}$ Reem Mohammed Al-Nasser, ${ }^{2}$ Asrar Qalt Alrashidi, 3Jameelah Sanad Fayez Al-Anazi \& 4Maram Qasem \\ Albalawi \\ 1,2,3,4 Department of Computer Science (Artificial Intelligence), University of Tabuk, Tabuk, Saudi Arabia. \\ "Corresponding Author: 431010436@stu.ut.edu.sa
}

Received: 02.01.2021, Revised: 05.03.2021, Accepted: 15.05 .2021 , Published: 16.08 .2021

DOI:

10.53409/mnaa/jcsit/2204

Abstract: Smart logistics is one of the most important advantages offered by Internet of Things technology. Logistics services seek to automate their work to reduce manual labour costs and take advantage of available technical services. In this research, we present the details of the administrative processes in the logistical fields, in addition to the details of the types of logistical services in general to clarify what the logistical processes are and how they are used. What is new is to mention that we will explain how the Internet of Things is used in the field of smart logistics, in addition to clarifying the most important studies in smart logistics services in the field of smart transportation, delivery and storage of products using the Internet of Things. Moreover, we discuss the most important developments in smart logistics services in the Kingdom of Saudi Arabia that it seeks to achieve in Vision 2030. In addition to discussing the most important technical components that the Kingdom of Saudi Arabia possesses for the success of smart logistics projects.

Keywords: Internet of Things, Smart logistics, RFID.

\section{INTRODUCTION}

he meaning of logistics services Logistics $\mathrm{T}$ is the science and management of the flow of different materials such as goods, energy, information, and various human services from the area of production to the area of consumption. It is difficult to carry out any global trade, whether it is import or export, or a process to transport various goods and resources without professional logistical support, and logistics services include several axes, including transportation, inventory, warehousing, physical processing, packaging or boxing [1]. The Oxford English Dictionary defines logistics as "the branch of military science related to the maintenance and movement of materials, personnel, and facilities". However, the New Oxford American Dictionary defines logistics as "the detailed coordination of a complex process involving many people, facilities, or supplies", and the Oxford Online Dictionary defines it as "the detailed organization and execution of a complex process". As such, logistics is generally viewed as a branch of engineering that creates "human systems" rather than "automated systems".

According to the Council of Supply Chain Management Professionals, logistics is the process of planning, implementing and controlling the efficient and effective transportation and storage of goods including services and related information from point of origin to point of consumption for the purpose of conforming to customer requirements and includes incoming, outgoing, inbound and outbound movements.

Academics and practitioners traditionally refer to the terms operations or production management when referring to the physical transformations that occur at a single business location (factory, restaurant or even a bank clerk) and reserve the term logistics for activities related to distribution, i.e., moving products over the area. Thus, the management of the distribution center is seen as related to the field of logistics, since in theory, the products made by the factory are ready for consumption, yet they still need to be transported along the distribution network according to some logic and distribution central aggregates and orders coming from different regions from the region. However, from a modelling perspective, there are similarities between operations management and logistics, and sometimes companies use dedicated professionals, for example an "operations manager" or a "logistics officer" who works on similar problems. Moreover, the term supply chain management originally referred to, among other things, having an integrated view of both production and logistics from the point of origin to the point of production. All of these terms may suffer semantic change as a side effect of advertising [2]. 
Currently, work is being done on smart logistics that relies on modern information and communication technology. The logistic system can be achieved through modern technologies with high efficiency, great speed and lower cost. Intelligent logistics can provide a comprehensive view, improve the way of logistics transportation, warehousing, distribution processing, distribution, information services, etc.

The Internet of Things plays a major role in managing logistics operations, as it works on changing the structure of previous systems and replacing more sophisticated systems in managing logistics operations. The Internet of Things provides control over all processes, starting from production, where sensors check raw materials and know the favourable conditions for production well. In addition, the Internet of Things helps in packaging operations, as it can detect errors that occur and strive to reduce the error rate. Moreover, it works on managing warehouses better, as it monitors incoming and outgoing products and production control [3].

The origin of logistics the word "logistics" comes from the ancient Greek language, which meant an account, a reason, or a letter. In 1991, the Board of Logistics Management in the United States of America defined the word logistics as the process of planning, implementing, controlling the flow, and storing the necessary goods, services and various information from the point of origin to the point of consumption in order to reach consumer satisfaction with the goods or service provided. As for the Oxford Dictionary For language, he defined this word as a branch of military sciences concerned with the transportation, management and preservation of various materials.

\section{BACKGROUND}

In this section we will display the objective of logistic service and the most type of logistic. The objectives of Logistics Services are,

- Improving the physical flow from source to estuary.

- Introduce the purchasing and production programs in a country.

- Organizing after-sales services and distributing various spare parts.

- Advise officials to enable them to make the most of business operations.

- Optimizing the investment.

- Help organizations to master the complexity and various problems.
- Creating an atmosphere of competition by providing better logistic services [4].

The different types of logistics are,

Administrative Logistics: This type is considered complementary to the well-known logistics services of transporting and supplying various materials, and is based on planning, implementing, auditing, and controlling the storage of different goods in a flexible manner. Third-party logistics, where the first party in this type of logistics receives goods for a particular company, arranges, stores, preserves, transports, and distributes it, and then the second party, or known as (a service developer) provides additional advanced services to customers, such as: search, follow-up and packaging. The private party, as for the third party, is the one who undertakes the logistics activities of the company but does not develop them, and the fourth party is the one who undertakes the development of the logistics activities applicable in the company.

Business Logistics: It is the logistics services provided in a specific field of work, such as: airlines. Production logistics: It is the services related to the production line such as transporting goods, supplying them, and distributing them.

Emergency Logistics: These are the services that are provided in the event of transportation of goods or products in emergency situations [5]. Considering the services performed by the logisticians, the main areas of logistics services can be divided as follows:

- Purchasing logistics.

- Distribution logistics.

- After-sales logistics.

- Disposal logistics.

- Reverse logistics.

- Green logistics.

- Global Logistics.

- Logistics of housemaids.

- Concierge Service.

- Reliability, availability and maintainability.

- Asset Control Logistics.

- POS Materials Logistics.

- Emergency logistics.

- Production logistics.

- Construction Logistics.

- Capital Project Logistics. 
- Digital Logistics.

- Humanitarian logistics.

Procurement logistics consists of activities such as market research, requirements planning, buy or sell decisions, supplier management, requisitions, and order control. Objectives in procurement logistics may be contradictory: to maximize efficiency by focusing on core competencies, outsource while maintaining company independence, or reduce purchasing costs while increasing security in the supply process. Advanced logistics consists of the activities required to prepare or make a plan for the logistical activities that take place.

Global Logistics is technically the process of managing the "flow" of goods through the so-called supply chain, from where they are produced, to other parts of the world. This often requires a multimodal transportation system, ocean, air, rail and truck transportation. This is perhaps one of the most complex and time-consuming forms of logistics. Logistics distribution tasks, as the main tasks, are the delivery of finished products to the customer. It consists of order processing, warehousing and transportation. Distribution logistics is essential because the time, place and quantity of production varies with time, place and quantity of consumption.

Reverse logistics refers to all those processes related to the reuse of products and materials. The reverse logistics process involves managing and selling surpluses, as well as returning products to sellers from buyers. Reverse logistics represents all operations related to the reuse of products and materials. It is "the process of planning, implementing and controlling the efficient and costeffective flow of raw materials, inventory in process, finished goods and related information from the point of consumption to the point of origin for the purpose of value recovery or proper disposal. More precisely, reverse logistics is the process of moving goods from their typical final destination with the purpose of Get the value, or dispose of it properly. The opposite of reverse logistics is forward logistics." Green Logistics describes all attempts to measure and reduce the environmental impact of logistics activities. This includes all forward and reverse flow activities. This can be achieved through multimodal freight transportation, route optimization, vehicle saturation and city logistics. RAM Logistics combines both business logistics and military logistics since it is concerned with highly complex technological systems for which reliability, availability and maintainability are essential, eg: weapons systems and military supercomputers.

Asset control logistics: Companies operating in retail channels, whether regulated retailers or suppliers, often deploy the assets required to display, maintain and promote their products. Some examples are refrigerators, suites, displays, seasonal equipment, and poster and frame stand.

Emergency logistics (or humanitarian logistics) is a term used by the logistics, supply chain, and manufacturing industries to refer to the specific, time-critical means of transportation used to quickly move goods or objects in an emergency situation [6]. The reason for the inclusion of emergency logistics may be production delays or anticipated production delays, or the urgent need for specialized equipment to prevent events such as grounding (also known as "Aircraft on the Ground" - AOG), communications delays or failures. Humanitarian logistics include governments, the military, aid agencies, donors, NGOs, and emergency logistics are usually obtained from a specialized provider.

The term production logistics describes the logistical processes within a value-added system (for example: a factory or a mine). Production logistics aims to ensure that each machine and workstation receives the right product in the right quantity and quality at the right time. Taking care of production, testing, transportation, warehousing and supply.

Production logistics can operate in existing and new plants: since manufacturing in an existing plant is a constantly changing process, machines are exchanged and new machines are added, giving the opportunity to improve the production logistics system accordingly [7]. Production logistics provides the means to achieve customer responsiveness and capital efficiency. Production logistics becomes more important as batch sizes decrease. In many industries (such as mobile phones), the short-term goal is a single batch size, allowing a single customer's demand to be efficiently met. Track and Tracing, which is an essential part of production logistics due to product safety and reliability issues, is also gaining importance, especially in the automotive and medical industries. Construction logistics has been employed by civilizations for thousands of years. Various human civilizations have also tried to build the best possible constructions for sustenance and protection. Construction logistics has now emerged as a vital part of construction. In the past few years, construction logistics has emerged as a different field of knowledge and study in the subject of supply chain management and logistics.

\section{KEY TECHNOLOGIES IN SMART LOGISTICS}

The Internet of Things (IoT) describes the network of physical objects - "things" - embedded with sensors, software, and other technologies for 
the purpose of communicating and exchanging data with other devices and systems over the Internet [8]. The Internet of Things is the main seed in the development of intelligent logistics services [9]. The idea of IoT is that many objects can communicate with each other to reach a specific goal with the help of sensors and data obtained during the operation of the system. The intelligent logistics system can obtain information on products, freight vehicles, transportation and storage methods at anytime and anywhere, and data can be sent from one party to another through the network.

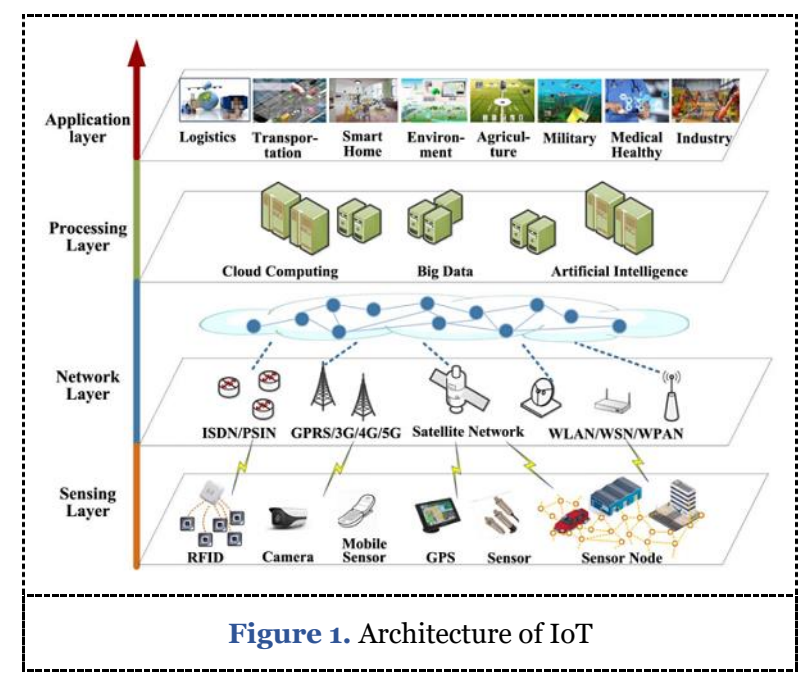

Systems that depend on the Internet of things consist of four layers as shown in Figure 1, namely the sensing layer, the network layer, the processing layer, and the application layer. The sensor layer collects data from the medium in which it is placed, such as temperature sensors, sound measurement sensors, color sensors, and others. The network layer connects devices to each other, as it communicates the collected data and sends it to the upper layer. The processing layer receives and stores data from the network layer and works on processing it using artificial intelligence algorithms. The application layer makes it easier for users to access the data being processed and allows them to control the settings of the previous layers [10].

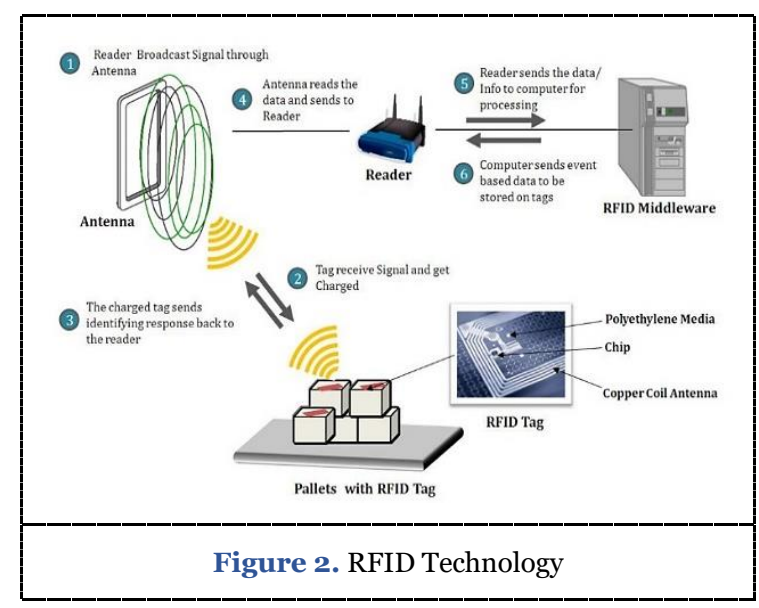

Stand-alone, RFID technology plays an important role in smart logistics projects, as hardly a project is devoid of the use of this technology in identifying products or vehicles and capturing information in various fields of logistics as shown in Figure 2.

This electromagnetic technology is used to detect objects, where Identification tags are placed on products and are detected from a distance of several meters. RFID tags store identifying information RFID tags store identifying information. RFID tags store identifying information e.g., product number, product name. It is worth noting that it can be equipped with sensors to perform a specific function, such as temperature sensors. According to the energy used, RFID types can be divided into two main types as follow:

Active Chips: This type is based on a battery the presence of the battery makes this chip communicate up to 100 meters. Some of these chips are completely independent of the reader field, as they are integrated with a special transmitting unit, which makes them able to communicate over a distance of several kilometres [11].

Passive chips: This type does not depend on a battery, the lack of an independent power source limits the transmitting power of these chips to only several meters, this chip is fed by electromagnetic wave energy. The reader's field capacity decreases rapidly with increasing distance, which limits its reading range to a distance of 4-5 meters using very high frequencies [11].

Wireless Sensor Network is a group of sensor nodes that are wirelessly connected to each other to collect data in a given environment. In logistics projects there are many sensor nodes that must work together to organize data collection and control terminals as shown in Figure 3. Therefore, WSN acquires great importance in solving the problems of logistics projects such as monitoring production lines, warehouses and transportation vehicles [12].

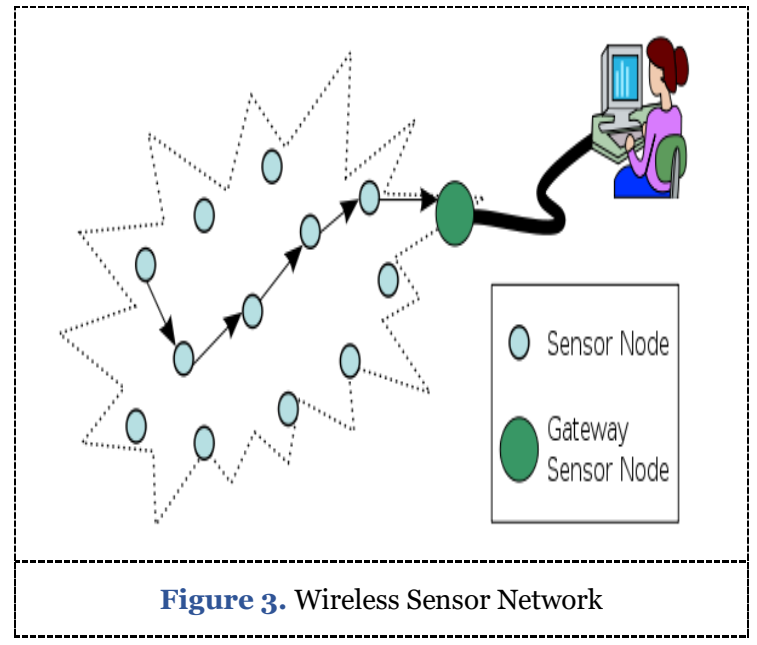


The elements used to configure a wireless sensor node are different units such as sensing, processing, transceiver, and power. It also includes additional application-dependent components such as power generator, positioning system, and packager. The sensors here produce analog signals that can be switched into digital signals through the "ADC", and then move to the processing unit [10].

Sensor Node Components: The sensor node is a device that contains a microprocessor and has the ability to monitor and wirelessly communicate, and it suffers from small memory size in addition to limited power reserve. The sensor node, as shown in Figure 4, consists of the following units [13]:

- Sensor unit.

- Data storage and processing unit.

- Transmitter \& Receiver unit.

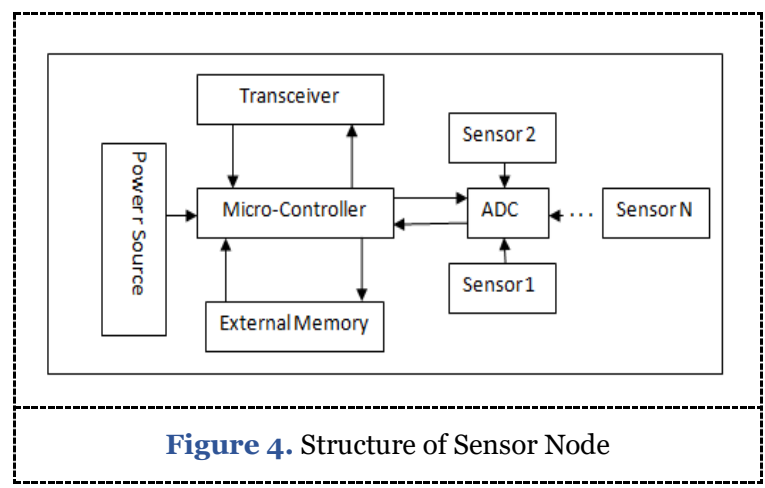

Energy: Modern applications in the fields of wireless sensors require, on the one hand, devices with a long lifespan, and on the other hand, these devices usually contain a limited source of power. Each sensor is usually supplied with two AA rechargeable batteries. Several factors affect the its energy consumption:

- The number of device inputs.

- Number of services.

- Transmit and receive time

- Ambient environmental conditions such as temperature.

- Accurate readings required.

- Radio waves used.

Memory Size: Sensors contain memory modules of small size, which leads to a short period of time required to store data before it is analyzed or sent to nearby devices. Older types of sensors also use memory technologies, both types SRAM and SDRAM, while new sensors contain these two types of the memory together, but they are integrated with the chip of the device itself, in addition to the use of an external memory.
Data Processing: The processor in the sensor plays an important role in analyzing and processing the data observed by the device itself or received by other devices, and after the completion of the analysis process, this data is sent in a message which may be encrypted to neighboring devices, and this requires controlling radio waves and dealing with a code message and stored. The processor performs another function, which is data collection, and this collection usually is the responsibility of a particular sensor that integrates local and received data, some of this collected data may be rejected and others may be sent to neighboring devices.

Connection: The broadcast device is one of the most important components of the sensor, and it is also the most energy consuming unit, as $97 \%$ of the energy consumed is related to transmission and reception, either using the broadcast unit directly or as a result of the processor waiting for the broadcast unit to finish sending or receiving [13].

Cloud Computing: Due to the complexities in logistics systems, traditional centralized methods may be limited in many parameters that must be considered such as computational effort, storage capacity, and sharing. Therefore, cloud computing represents a flexible solution for logistics services to facilitate communication between all components as they can be accessed from anywhere and provide storage capacities and a very large computational effort [14].

So, cloud computing offers many services, whether for companies or individuals. Figure 5 show the most important resources offered by cloud computing (for example, networks, servers, storage, applications, and services). It is worth noting that cloud computing users do not need maintenance or resource management, and their information will not be damaged or lost. Cloud computing has five main characteristics (self-service on-demand, wide network access, resource aggregation, rapid resilience, and scaled service).

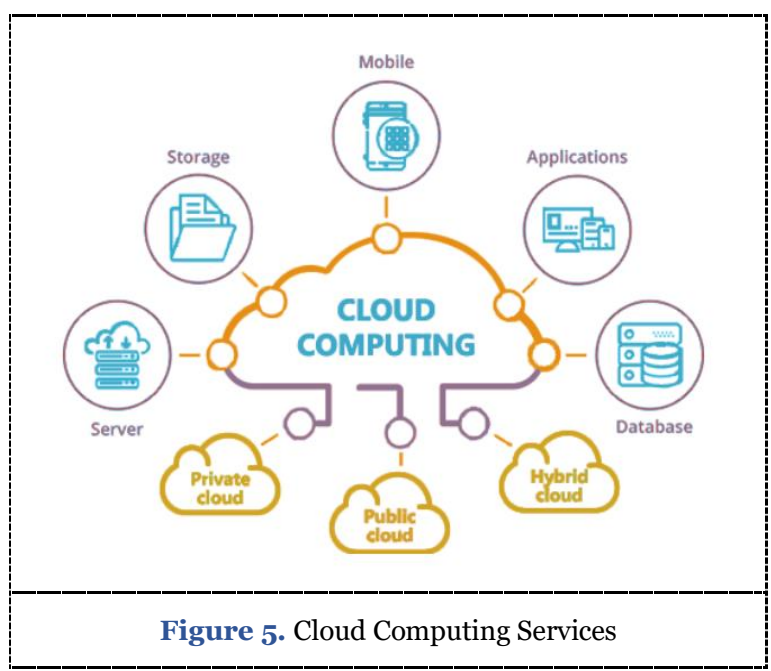


Moreover, computing has different models, the most important of which is software as a service - SaaS, which is the ability of consumers to use software without having to purchase it, as the cost is based on use. Infrastructure as a Service - IaaS is the ability of consumers to use processing, storage, networking, and other basic computing resources where the consumer is able to deploy and run software, which can include operating systems and applications [15].

\section{APPLICATIONS OF IOT IN SMART LOGISTICS}

In this section, we focus on the most important applications of IoT technologies in smart logistics

Smart Logistics Transportation: The study [16] suggested using the genetic algorithm in planning the most appropriate path for the distribution staff. The study also used some criteria in annealing algorithms to determine the paths that enter into each stage. The simulation results showed that it effectively shows the optimal solution, moreover, it shortens the execution time to one third of the original time.

The paper [17] proposed a new algorithm to work on determining the path of the AGV (Automated Guided Vehicle) to sort parcels and deliver them to the specified places. The pathplanning algorithm to the discharge port is designed based on passive RFID technology, which allows identifying the discharge locations. The algorithm identifies the multiple paths of the AGV and also solves the potential intersection conflict and pitfall that may arise when the system is running. The algorithm has been successfully tested by simulation experiments.

The study [18] proposed an ant colony algorithm that searches for optimal solutions among the set of available solutions, similar to the way ants search and track. The algorithm tests the best possible transport vehicle among the many available vehicles. It can improve vehicle steering path and shorten delivery time. It is worth noting that this algorithm effectively addresses the problems that appear in the traditional vehicle scheduling method. The algorithm was tested on simulation software, and it showed excellent results in improving express delivery orders.

The study [19] suggested using dynamic programming equations for the delivery and receiving process in order to improve the efficiency of the express logistics process. The study assumed the creation of a TSP problem model, and sought to choose the shortest way to reach the goal of cost reduction. The study has not been practically implemented and has not been simulated by any software, so the algorithm must be validated in express logistics to prove the validity and feasibility of the algorithm.

Smart warehousing: The study [20] presented a system that automates warehouses based on IOT, artificial intelligence, sensor networks, and cloud computing. RFID technology identifies the type of goods received and barcodes are used for the variety of products. It is worth noting that the information of incoming and outgoing goods is automatically recorded in the computer connected to the network and cloud computing. The robots work with the technology of raging ants to draw the shortest path to reach the specified product in the warehouse. Moreover, the robot is equipped with cameras that process the image and use the sensors so that they do not collide with each other.

The study [21] proposed a system that works specifically as a low-volume high-mix scenario based on the Internet of Things and RFID technologies to monitor the warehouse. The proposed system receives customer requests and checks raw materials if they are available. It issues orders to the system to start production, unless it issues purchase orders automatically in the quantities necessary to produce the order. The proposed system works to track the status of orders and know the production statuses. Moreover, the proposed system is equipped with fuzzy logic technology to suggest the most appropriate method for selecting orders in order to enhance production efficiency.

The paper [22] describes the concept of intelligent warehouses that use artificial intelligence and optimization algorithms that include inventory planning based on prediction algorithms that use company data from 20 years ago. In addition, the system works to receive products and localize them in the warehouse, where it works to localize similar products in close places based on SQL procedures. The system issues the products according to the expiration date, as the products with the closest expiration date are the ones that are sold first. The system results showed a $40 \%$ improvement in the order picking process, and the number of items with an expiration date reached a minimum.

An intelligent logistics system based on the Internet of things was discussed [23] to monitor drug preparation laboratories and monitor their transportation until they reach your point of sale. The proposed system consists of two layers: The first layer contains the Radio Frequency Identifications (RFID), which works on identifying medical products and tools. The second layer is a wireless sensor network that connects nodes in the system to transmit data between nodes. The main nodes in the system are equipped with RFID and GPS readers to locate trucks during transportation. 
The study [24] discussed the most important technologies of the Internet of Things that can be associated with the automation of business processes and their use in logistics services. The most important technologies presented by the study are Radio Frequency Identification (RFID) and Wireless sensor networks. Moreover, the study presented the limitations of Business Process Execution Language (BPEL) to define business processes.

Smart Packing: It is the process of linking information about materials and machines to the Internet via a computer, to facilitate communication between them and other elements. The process of smart packaging takes place in two ways:

- The contribution of machines in exchanging information and increasing efficiency during the production and packaging process.

- Interactive packaging technology that gives the consumer the opportunity to interact with the products.

In this way, the packaging and the packaging itself can exchange information, through a direct contact service with the consumer. Smart packaging systems also help track products at all stages of logistics and distribution channels, in addition to increasing consumer participation and satisfaction, as the consumer who reads the code printed on the product can access detailed information about it and its nutritional value or whether it is counterfeit.

With current digital systems, the consumer can directly access the brand's consumer advisory group, to obtain information about the product, ensure customer satisfaction, and make marketing measurable. Additionally, once the consumer reads the code from their smartphone, it is easy to direct promotional messages to them. Going a step further, a sensor feature can be added in the package, to give the consumer the ability to know whether the package was opened or filled later during the sale, or to check whether the temperature of the package is in the required range and check the expiry date, through smartphones or tablets. This property has gained great importance, especially in the food and pharmaceutical industries.

Intelligent packaging logistics is a global network that constantly communicates with the outside world through scanners and mobile devices and can be machine-readable by radio waves, allows separate product information to be tracked and updated, and adds detailed information throughout the product lifecycle, has become a necessary and mandatory policy Especially for health and basic products. These systems also give great solutions to attract the consumer, share the brand, protect it from monitoring and improve production processes, thanks to which the information does not move only in one direction, as it creates an interactive platform between the producer and the consumer.

With the ability to give all products different codes, companies are increasingly using RFID technology and are subsequently read by fixed or portable readers. Moreover, this technology offers the possibility of freedom of immediate monitoring of data for processing, storage and preparation of analytical reports for the activities of the products. Noteworthy, intelligent packaging reduces labor costs by up to $50 \%$, inventory costs by $30 \%$, in-store losses by $20 \%$ and inventory times by up to $80 \%$. Global demand for electronic smart packaging features is expected to be $\$ 895$ million in 2030, down from $\$ 55$ million in 2020, and that there will be more if infrastructure, software, and services are included. To have an electronic specialty to improve packaging in 2030, with about 21 billion packages sold in 2030 [25].

New technologies have improved supply chain operations in various industries and markets, increasing product identification and monitoring, and ensuring unimaginably clear capability for managers of large and small brands. In fact, new technologies are a wealth because they increase consumer experience with packaging, because new technology is forcing companies to be more transparent in clarifying information about what the packaging is and how to dispose of it, because the needs of consumers in the 21st century are moving in this direction.

Active Packaging: Active Packaging of Food technologies have transformed basic packaging processes from inactive packaging whose function is only to act as a barrier protecting packaged food from microbial, chemical, oxygen, moisture and light contamination to active packaging whose function is to act as an interactive system between the packaged product, the packaging and the surroundings.

All active food packaging technologies involve physical, chemical or biological action to modify the interactions between packaging, product, and apical space in the packaging to achieve specific desired results. Active food packaging technologies include three main groups:

- Absorbers and Scavengers.

- Emitters.

- Other Active Technologies.

Smart technologies for food packaging: Smart food packaging technologies are defined as a system characterized by their ability to perform smart functions such as detection, sensing, recording, tracing, communication and applying scientific logic to facilitate the decision-making 
process to extend the shelf life, ensure safety, improve quality, provide the necessary information and alert potential problems. The ability to communicate is one of the most important functions of smart packaging because the packaging and the packed food move together during the cycle of the distribution chain, and thus communication provides an important possibility in terms of knowing the status of the packed food.

Smart packaging systems use small, inexpensive devices that are labels or labels that are attached either to primary packaging (such as sterile bags, plastic packages, trays, and glass and plastic bottles) or to secondary packaging (such as outer cartons or shipping packages in ships and reefer containers). and others) to facilitate the communication process through the transmission and distribution chain [26]. There are two types of smart packaging systems:

- Package Indicators Systems as shown in Figure 6.

- Data Carrier Systems as shown in Figure 7.
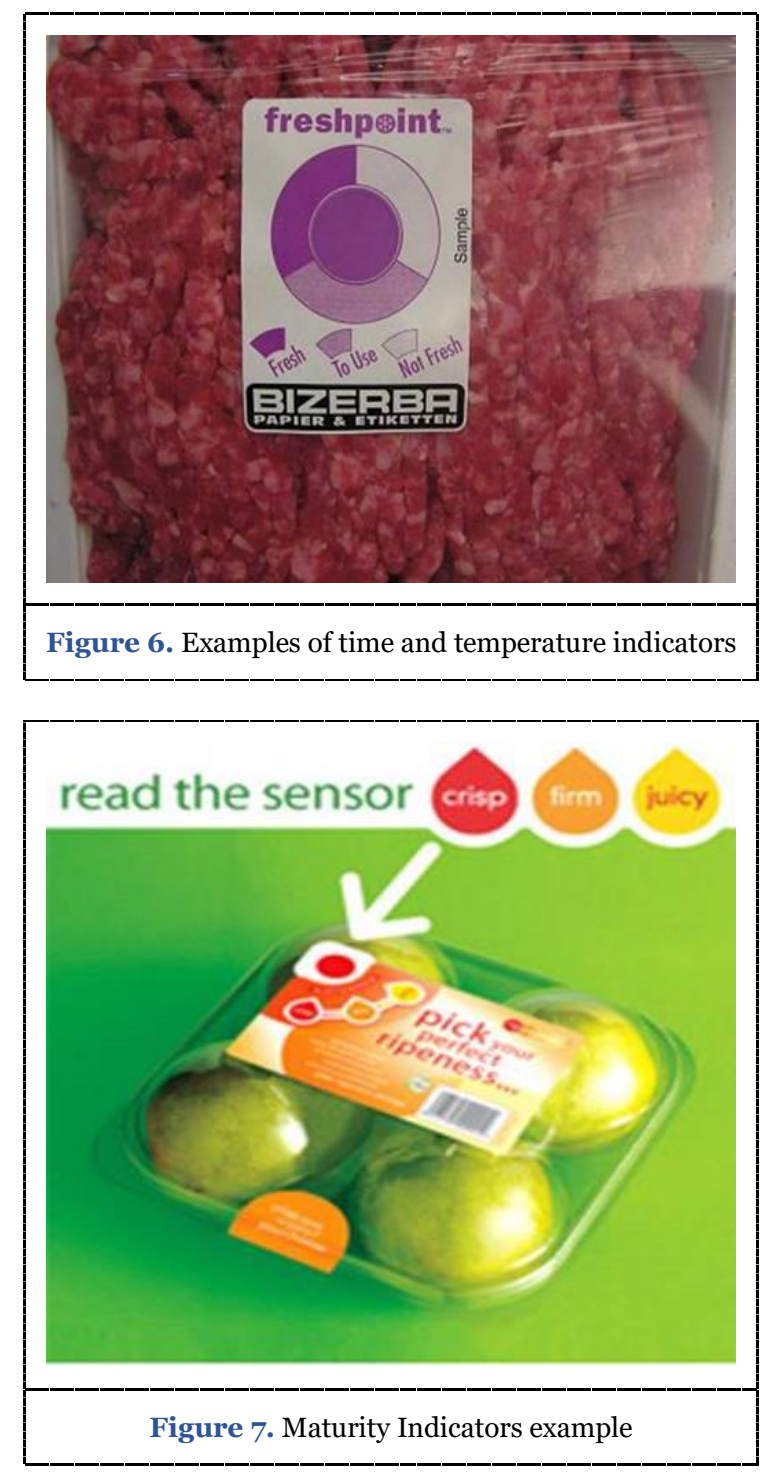

The World Bank [28] [29] describes in the Logistics Performance Index (LPI) in the Kingdom of Saudi Arabia as low, with a cumulative rate of 3.16 out of 5 , or $63 \%$ as shown in Figure 8. Shipping and transportation, tracking shipments in real time, and finally the time or schedule of shipments. The Kingdom's ranking in this indicator comes at 52nd place after we were 49th in 2014 and 41st in 2007, meaning that this sector is regressing backwards in the KSA as shown in Figure 8.

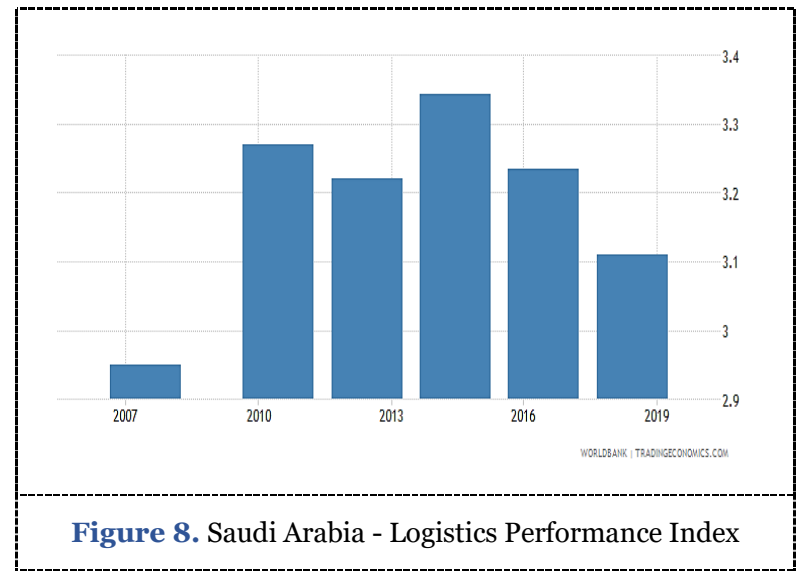

Smart Logistics in Saudi Arabia: Crown Prince Mohammed bin Salman launched the National Transport and Logistics Strategy in July 2021 [30] to implement the goals of Vision 2030. This strategy will enhance technical capabilities in the fields of technology, communications and transportation in Saudi Arabia. It is worth noting that it will enhance the link with the global economy and enable the Kingdom to exploit its strategic location, which links between Asia and Europe, making Jeddah Islamic Port and Dammam Port a link between East and West, and this is a competitive advantage that most Gulf countries lack. In addition, it will reduce the proportion of employment in the industrial and commercial sectors to a significant level.

The study [31] discussed the impact of the application of the Internet of Things on various fields in the Kingdom of Saudi Arabia and the challenges and security threats that can be faced. Moreover, the study suggested a model for the acceptance of the Internet of Things in the Kingdom of Saudi Arabia based on theories of information systems such as (TAM and UTAUT). The results of the statistical analysis indicate that the Internet of Things is acceptable in the Kingdom of Saudi Arabia.

The paper [32] aimed to analyze the levels of logistics services in the Kingdom of Saudi Arabia, discover weaknesses and suggest solutions to improve the performance of logistics services. The study also proposed an integrated framework that uses cloud computing and Blockchains to improve the performance of logistics services and reduce 
their costs. The study used the K-mean algorithm to make comparisons between the performance of logistics services in Saudi Arabia with neighboring countries.

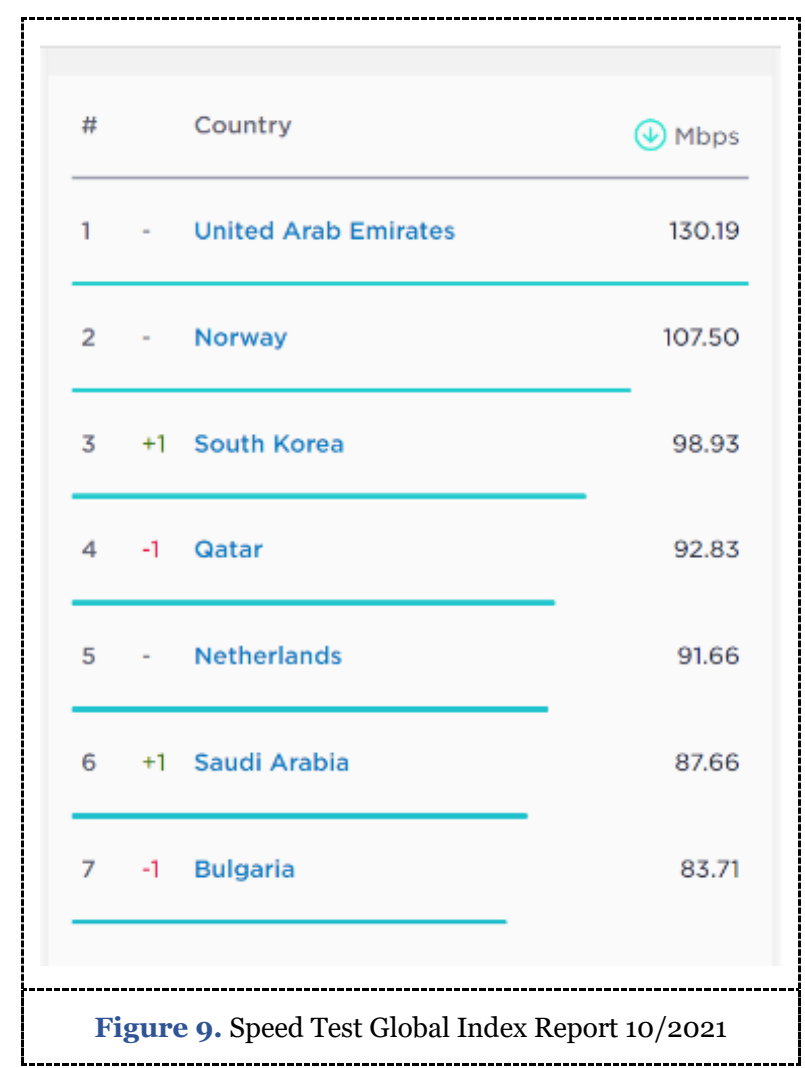

Auxiliary factors for logistics services in the KSA: KSA has many ingredients that make logistics projects succeed and overcome difficulties as follows:

Internet coverage: Saudi Arabia ranks sixth in the speed test Global Index report as shown in Figure 9 [33]. It is expected that the Internet will cover $97 \%$ of Saudi lands as shown in Figure 10.

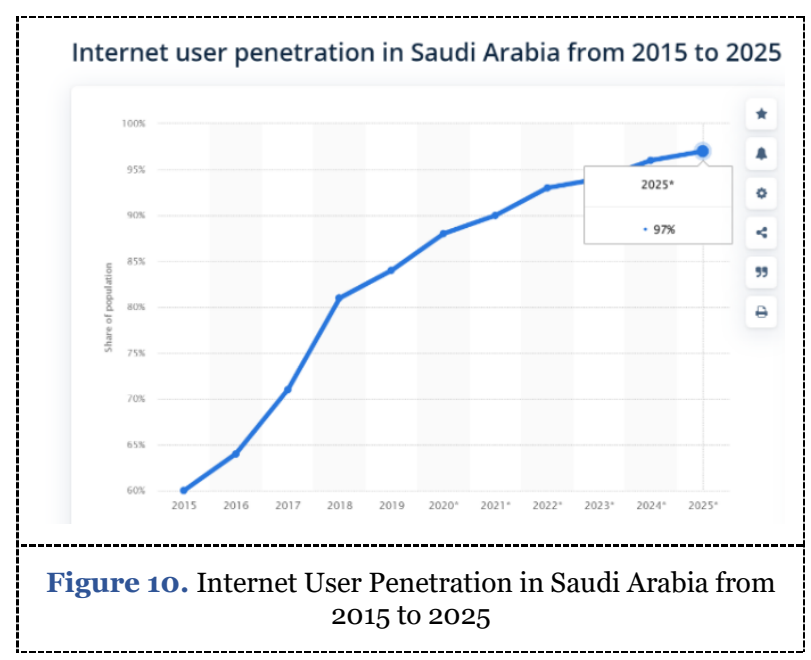

Advance payment service: Many advanced banking and payment services are available in the
Kingdom of Saudi Arabia such as credit cards and electronic wallets such as "STC pay" and "Halala". Smartphone applications such as MADA pay and Apply Pay and other services are also available that have facilitated e-commerce and are sure to facilitate the work of smart logistics services.

Reliable network of roads and services: In the past years, the Kingdom of Saudi Arabia has developed a large land, sea and air transport network. It is worth noting that the Crown Prince launched a strategy that aims to make Saudi Arabia a global route for passenger transport. The extensive road network and traffic police management are all factors that help in the success of smart logistics projects.

\section{CONCLUSION AND FUTURE WORK}

The Internet of Things has greatly helped in the development of logistics services. In this study, the most important technologies that contributed to the development of smart logistics services, such as the Internet of things, sensor network and cloud computing, were presented. In addition, the most important applications of smart logistics services, which are smart transportation and smart warehouse management, were presented. It is worth noting that Vision 2030 was discussed in the field of smart logistics services. They also discussed the potentials owned by the Kingdom of Saudi Arabia that contribute to the development of smart logistics services.

The data in the study shows that the Kingdom of Saudi Arabia has the ingredients that make it in the list of Arab and regional countries in the field of smart logistics services. The most important of these components are the speed of the Internet, the areas it covers, and the easy payment services provided by various banks. It is worth mentioning is the government's interest in all fields, including logistics, which was inaugurated by Prince Mohammed bin Salman and the start of work on smart logistics projects [31].

ETHICS APPROVAL AND CONSENT TO PARTICIPATE

Not applicable.

HUMAN AND ANIMAL RIGHTS

No animals/humans were used for studies that are basis of this research.

CONSENT FOR PUBLICATION

Not applicable.

AVAILABILITY OF DATA AND MATERIALS 
The authors confirm that the data supporting the findings of this research are available within the article.

\section{FUNDING}

None.

\section{CONFLICT OF INTEREST}

The authors declare no conflict of interest, financial or otherwise.

\section{ACKNOWLEDGEMENTS}

The authors would like to thank their present employer for providing support while carrying out this research work.

\section{REFERENCES}

[1]. W. Kenton. Logistics. Investopedia, 29 Dec 2020. [Online]. Available: https://www.investopedia.com/terms/l/logistics.asp. [Accessed 11 Nov 2020].

[2]. V. Misra. Supply Chain Management Systems: Architecture, Design and Vision. Journal of Strategic Innovation and Sustainability, 2010, 6(4), 96-101.

[3]. Ashton Kevin. That 'internet of things' thing. RFID Journal, 2009, 22(7), 97-114.

[4]. Kherbach O, Mocan ML. The importance of logistics and supply chain management in the enhancement of Romanian SMEs. Procedia-Social and Behavioral Sciences, 2016, 221, 40513 .

[5]. Carbone V, Rouquet A, Roussat C. Carried away by the crowd: what types of logistics characterise collaborative consumption. In 1st International Workshop on Sharing Econom, Utrecht, Netherlands, 2015.

[6]. Cozzolino, Alessandra. Humanitarian logistics and supply chain management. Humanitarian logistics. Springer, Berlin, Heidelberg, 2012, 5-16.

[7]. Nyhuis, Peter, and Hans-Peter Wiendahl. Fundamentals of production logistics: theory, tools and applications. Springer Science \& Business Media, 2008.

[8]. Lampropoulos, Georgios. Internet of Things in the Context of Industry 4.0: An Overview. International Journal of Entrepreneurial Knowledge, 2019.

[9]. Zainab H. Ali,Hesham A. Ali,Mahmoud M. Badawy, Internet of Things (IoT): Definitions, Challenges and Recent Research Directions. International Journal of Computer Applications, 2015, 128(1), 37-47.

[10]. Luong, Nguyen Cong Hoang, Dinh Thai Wang, Ping Niyato, Dusit Kim, Dong In Han, Zhu. Data Collection and Wireless Communication in Internet of Things (IoT) Using Economic Analysis and Pricing Models: A Survey. IEEE Communications Surveys and Tutorials, 2016, 18(4), 2546-90.

[11]. R. Angeles. RFID Technologies: Supply-Chain Applications and Implementation Issues. Information systems management, 2005, 22(1), 51-65.

[12]. Yanxing Song, F. Richard Yu, Li Zhou, Xi Yang, and Zefang He. Applications of the Internet of Things (IoT) in Smart Logistics: A Comprehensive Survey. IEEE Internet Of Things Journal, 2020.

[13]. John Munyakayanza, Evariste Twahirwa, Jane Murerwa. Demonstration of Queue Management with Differentiated Services in Wireless Sensor Networks (WSN). International Journal of Advanced Research in Computer and Communication Engineering, 2017.
[14]. A. Schuldt, K. A. Hribernik, J. D. Gehrke, K.-D. Thoben, O. Herzog. Cloud Computing for Autonomous Control in Logistics. Informatik 2010, 2010.

[15]. Katarzyna Nowicka. Smart City logistics on cloud computing model. Procedia-Social and Behavioral Sciences, 2014, 151, 266-281.

[16]. Wang Shuqi and Li Yan. A Path Planning Algorithm in Express Delivery Services. In 2019 International Conference on Intelligent Transportation, Big Data \& Smart City (ICITBS), 2019, 334-337.

[17]. Jianqiang Mei, Yiran Zhou. Research and Design of a Path Planning Algorithm in the Intelligent Logistics Sorting System. In 2018 IEEE 3rd Advanced Information Technology, Electronic and Automation Control Conference (IAEAC), 2018, 2008-2012.

[18]. ZHENG Jiajia, GU Zhenyu. Research on Express Delivery Vehicle Route Planning Method for Stochastic Customer Demand. In 2017 IEEE 2nd Information Technology, Networking, Electronic and Automation Control Conference (ITNEC), 2017, 783-787.

[19]. Kaixin Shi, Hengwen Zhang, Zuozhen Zhang, Xiaoguang Zhou. The Algorithm of Terminal Logistics Path Planning Based on TSP Problem. In 2020 International Conference on Artificial Intelligence and Computer Engineering (ICAICE), 2020, 130133 .

[20]. A. P. Pandian. Artificial Intelligence Application in Smart Warehousing Environment for Automated Logistics. Journal of Artificial Intelligence and Capsule Networks, 2019, 1(2), 63-72.

[21]. C.K.M. Leea, Yaqiong Lvb, K.K.H. Nga, William Hoc and K.L. Choya. Design and application of Internet of things-based warehouse management system for smart logistics. International Journal of Production Research, 2018, 56(8), 2753-68.

[22]. Emir Žunić, Sead Delalić, Kerim Hodžić, Admir Beširević, Harun Hindija. Smart Warehouse Management System Concept with Implementation. In 2018 14th Symposium on Neural Networks and Applications (NEUREL), 2018, 1-5.

[23]. M. Pachayappan, Nelavala Rajesh, G. Saravanan. Smart logistics for pharmaceutical industry based on Internet of Things (IoT). In International Conference on Advances in Computational Intelligence and Communication (CIC 2016), 2016, 31-36.

[24]. Pedro Ferreira, Ricardo Martinho, Dulce Domingos. IoTaware business processes for logistics: limitations of current approaches. In INForum 2010, 611-622.

[25]. Mirza Alizadeh A, Masoomian M, Shakooie M, Zabihzadeh Khajavi M, Farhoodi M. Trends and applications of intelligent packaging in dairy products: a review. Critical Reviews in Food Science and Nutrition, 2020, 1-5.

[26]. D. B. Hussein. Traditional, Active, and Intelligent Food Packaging Technologies.

[27 [مال صحيفة 2030 ورؤية اللوجستية الخدمات" ,البو اردي .ع .ب .خ. Dec 2016. [Online]. Available: https://maaal.com/archives/201612/84922/. [Accessed 24 Nov 2021].

[28]. T. Tconomics. Saudi Arabia - Logistics Performance Index. Trading Tconomics, [Online]. Available: https://tradingeconomics.com/saudi-arabia/logisticsperformance-index-quality-of-trade-and-transport-relatedinfrastructure-1-low-to-5-high-wb-data.html. [Accessed 24 Nov 2021].

[29]. World Bank. Logistics performance index: Quality of trade and transport-related infrastructure (1=low to 5 =high) - Saudi Arabia. World Bank, [Online]. Available: https://data.worldbank.org/indicator/LP.LPI.INFR.XQ?end=2 018\&locations $=S A \& s t a r t=2007$. [Accessed 24 Nov 2021] .

[30]. Government. HRH Crown Prince Launches National Transport and Logistics Strategy, One of Vision 2030 Pillars. Eye 
of Riyadh, 30 June 2021. [Online]. Available: https://www.eyeofriyadh.com/news/newsdetail.php?newsid=11 9801. [Accessed 24 Nov 2021].

[31]. A. Albesher. IoT Use Prevalence and Acceptance modelling in The Kingdom of Saudi Arabia. International Journal of Advanced Research in Computer and Communication Engineering, 2019.

[32]. B. A. Alyoubi. Clustering Analysis of Logistics Performance in Saudi Arabia: A Roadmap to Cloud Computing and IoT \& Blockchain Solutions. International Transaction Journal of Engineering, Management, \& Applied Sciences \& Technologies, 2021, 12(7), 1-4.

[33]. statista. Internet user penetration in Saudi Arabia from 2015 to 2025. statista, [Online]. Available: https://www.statista.com/statistics/484930/internet-userreach-saudi-arabia/. [Accessed 24 Nov 2021].

[34]. Rishmita Saha, Mahasweta Kundu, Madhuparna Dutta, Rahul Majumder. A Brief Study on Evolution of Iris Recognition System. In 2017 8th IEEE Annual Information Technology, Electronics and Mobile Communication Conference (IEMCON), $2017,685-688$. 